\title{
Mito y realidad en la saga de videojuegos Assassin's Creed
}

\section{Mito y realidad en la saga de videojuegos Assassin's Creed}

\author{
Susana Cuartero Escobés \\ Universidad de Zaragoza, España \\ scescobes@gmail.com
}

Recepción: 15 de octubre de 2018/Aceptación: 10 de noviembre de 2018.

doi: https://doi.org/10.15517/rehmlac.v10i2.35295

Palabras clave

Credo del asesino; caballero templario; masonería; videojuego; conspiración internacional.

Keywords

Assassin's Creed; Templar Knight; Freemasonry; Videogame; International Conspiracy.

Resumen

A lo largo de estas páginas vamos a intentar explicar cómo y porqué aparece la iconografía masónica en la saga de videojuegos de Assassin's Creed. La identificación de esa simbología con la Orden del Temple, a su vez, enfrentada con los Hashshasins, ha contribuido a alimentar el mito de la teoría de la conspiración internacional.

\begin{abstract}
Throughout these pages we will try to explain how and why the Masonic iconography is showed in the Assassin's Creed videogame series. The identification of these symbols with the Order of the Knights of the Temple, at the same time, faced with the Hashshasins has helped feed the myth of the international conspiracy theory.
\end{abstract}

\section{Introducción}

\section{"Actuamos entre las Sombras para servir a la Luz. Somos Asesinos".}

Hace unos años, en noviembre de 2007, apareció el primer videojuego de la saga Assassin's Creed. Por aquel entonces no le presté ninguna atención dado que no soy aficionada a este tipo de entretenimiento. Sin embargo, algunas secuencias y escenas llamaron mi atención por su similitud con unas imágenes que los estudiosos de la masonería tenemos muy interiorizadas. Estoy hablando de los «triángulos», bien sean en su forma geométrica, bien a través de algún objeto como la escuadra o el compás.

Todavía debieron transcurrir unos años y unas cuantas entregas de la saga para que me interesara saber qué había detrás de aquella iconografía.

El objeto de este artículo se centra precisamente en eso, en intentar comprender el porqué de la utilización de estos símbolos, con qué contenido esotérico se les ha querido 
identificar, o qué trasfondo político, social o incluso religioso se les ha querido atribuir, más allá de lo que en principio representan las tres líneas unidas por tres vértices.

Aunque este es nuestro propósito, no hay que perder de vista la carencia de fuentes que nos acercan al tema. Mayoritariamente, son los foros de gamers los que nos han ido proporcionando las opiniones e ideas que se suscitan alrededor de los dos principales grupos presentados en los juegos: Assassins $^{1}$ y templarios; y precisamente ha sido ahí donde hemos descubierto cómo de actuales son estos temas en el siglo XXI, y cómo la fantasía envuelta en falta de información, da lugar a inexactitudes históricas difícilmente desmontables, pero que por repetidas acaban convirtiéndose en "certezas".

Otro tipo de fuente empleada para centrar la trama son las diferentes novelas de Oliver Bowden ${ }^{2}$, quien realmente pone diálogos a los mismos personajes y escenas de los videojuegos, de modo que resultan muy amenos y fáciles de seguir. No obstante, todo parece indicar que la trama original está basada en la novela Alamut, de Vladimir Bartol ${ }^{3}$, que relata la historia de Hassanibn Sabbah y los Hashshashin. Otras novelas abordan temáticas parecidas y cercanas: El péndulo de Foucault, de Umberto Eco; El Libro del Edén, de Kay Meyer; Ángeles y Demonios, de Dan Brown, etc. pero en todas ellas hay un denominador común: son ficción y no se ajustan a la realidad.

Sin embargo, no hemos encontrado ninguna reseña, ni siquiera buceando en los entresijos de Ubisoft, que nos aproxime a las pretensiones de la compañía canadiense a la hora de producir los videojuegos, de modo que no podemos aventurar si tan solo buscaba distraer o albergaba algún otro fin.

\section{Para centrar el tema}

Como ya apuntamos, el primer videojuego de la serie fue publicado en $2007^{4}$ para todas las plataformas del momento. Desde entonces, los títulos aparecidos nos transportan de las Cruzadas al Caribe durante la edad de oro de la piratería; de la Revolución Francesa a la Industrial o del Egipto tolemaico a las guerras del Peloponeso ${ }^{5}$.

\footnotetext{
${ }^{1}$ A lo largo del trabajo nos referiremos a este grupo por su nombre en inglés Assassins por ser menos impactante que en español.

${ }^{2}$ Oliver Bowden es el seudónimo bajo el que Anton Gill publica las novelas de esta saga. Es un autor británico graduado en Literatura Inglesa y especialista en Historia del Renacimiento, autor de otras novelas históricas y de ficción, The Journey Back from Hell (1988); Berlin to Bucharest, The Egyptian Mysteries etc. además de las ya citadas de Assassins.

${ }^{3}$ Vladimir Bartol (Trieste, 1903 - Liubliana, 1967). Alamut fue publicada en 1938, en esloveno, y ofrece una visión del islam y de los regímenes totalitarios, perfectamente aplicables al presente.

${ }^{4}$ El primer videojuego titulado Assassins Creed se publicó el 16 de noviembre de 2007. El último, por ahora, Assassins Creed: Odyssey, el pasado 5 de octubre de 2018. Todos han sido distribuidos por la compañía francesa Ubisoft, que cuenta con tres empresas desarrolladoras, siendo la principal para esta serie, Ubisoft Canada.

${ }^{5}$ Se puede consultar en la siguiente dirección: https://vandal.elespanol.com/sagas/assassins-creed
} 
Con el transcurso de los años el fenómeno Assassins ha ido extendiendo su influencia a novelas, comics, cortometrajes, a un largometraje $\mathrm{e}^{6}$ y a todo tipo de artículos de uso cotidiano.

Los juegos han sido catalogados como de ficción histórica, acción, aventura y sigilo. Este último calificativo será retomado más adelante, cuando entremos en el análisis de los grupos protagonistas y antagonistas. De momento nos centraremos en intentar averiguar qué hay detrás de la historia $\mathrm{y}$, sobre todo, cuánto de realidad y cuánto de ficción. No en vano, todos los juegos comienzan con la leyenda: "Inspirada en hechos y personajes históricos. Esta obra de ficción ha sido diseñada, desarrollada y producida por un equipo multicultural que profesa credos y religiones distintas".

Previo a entrar en el análisis del juego, estableceremos una serie de límites, por no ser objeto de este trabajo, no sin antes reconocer la magistral recreación de los diferentes escenarios y el cuidado detalle de los ambientes por los que transcurre la acción. Lugares en los que el arte reside en cada imagen, desde catedrales góticas a mezquitas otomanas, desde el Carnaval de Venecia, a la Roma eterna y en los que se pasa de sórdidos asesinatos al misticismo más intangible. La primera de estas limitaciones es que no nos vamos a referir en ningún momento a cuestiones técnicas, gráficos, sonidos, etcétera; tampoco, y esta es la segunda, entraremos en cuestiones de jugabilidad: no nos interesa si las peleas están bien reproducidas o no, si los personajes pueden ir más o menos deprisa, mejorar el parkour y los «saltos de fe», o si Altaïr es más carismático que Ezio y este que Connor. Finalmente, la tercera es que solo nos vamos a centrar en las cinco primeras entregas que componen la serie porque a través de su protagonista, Desmond Miles, completan un ciclo en sí mismas: Altaïr en las Cruzadas; Ezio en Florencia, Venecia, Roma y Constantinopla, durante el Renacimiento; y Connor en la Revolución Americana.

\section{Assassins versus templarios: entre la leyenda y la realidad}

La historia gira en torno al conflicto entre los dos grupos y se inicia en una época clave en la historia de la humanidad, las Cruzadas, un momento dominado por la importancia de las religiones en pugna y en expansión y por lo tanto de la lucha entre lo humano y lo divino. Una trama argumental no muy elaborada, de buenos contra malos, en la que el verdadero atractivo son los integrantes de ambos grupos, antagónicos en la ficción, no tanto en la realidad. Hay que tener en cuenta que la expansión de los nazaríes hacia Siria chocó con la de los templarios y en ocasiones, se vieron obligados a firmar pactos y alianzas.

\footnotetext{
${ }^{6}$ Assassin's Creed (2016), dirigida por Justin Kurzel, y protagonizada por Michael Fassbender, ambientada en
} la España de finales del siglo XV, en pleno auge de la Inquisición española. 


\section{Assasins}

Nacidos tras un cisma religioso en el seno del islam, concretamente en la comunidad chiita de los ismaelitas, los Hashshashin seguidores del antiguo imán Hassan ibn Sabbah, también conocido como "el Viejo de la Montaña", se asentaron en la zona del actual Irán, desde donde intentaron expandirse, y se les denominó nazaríes. Sus detractores les otorgaron el despectivo calificativo de hashashin-fumadores de hachís-, con el que han pasado a ser conocidos ${ }^{7}$.

Se trataba de un grupo organizado especializado en amenazar y asesinar de modo selectivo lo cual, además de provocar un estado de paranoia continua, les granjeó numerosos enemigos. Entre las víctimas en las filas cristianas se encontraron Raimundo II de Trípoli, Conrado de Monferrato, rey de Jerusalén, Isabel de Armenia y Felipe de Montfort, entre otros. Del lado musulmán cayeron numerosos sultanes, el mismo Saladino salvó su vida de casualidad, sin embargo, todo se complicó tras el asesinato de Chagatai, uno de los hijos de Gengis Kan. Los mongoles atacaron sus principales cuarteles generales Alamut y Masyaf y los hashashin se vieron obligados a huir y a desperdigarse, perdiendo así todo su poder.

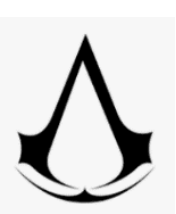

En los juegos son perfectamente reconocibles por su emblema.

Para algunos el logotipo representaría la punta de la daga que constituye la hoja oculta, arma utilizada para asesinatos sigilosos ${ }^{8}$.

Para otros, representaría la mayúscula de la letra griega "Delta" $\Delta$ y vendría a significar una variable, un cambio grande. Un tercer grupo, el más numeroso, piensa que no es sino la letra "A" de Assassin, pero ornamentada y lo aproximaría a cierto conocimiento esotérico presente en casi todas sociedades iniciáticas, hermandades, sociedades secretas, etc., no en vano los muchachos que eran reclutados para convertirse en Assassins debían recibir una férrea formación militar y psicológica, al ser sometidos a duras pruebas.

\footnotetext{
${ }^{7}$ Debemos poner en duda que actuaran bajo los efectos de las drogas, en este caso el hachís, ya que sus actuaciones requerían precisión y sigilo. $\mathrm{Y}$ ambas acciones no son compatibles con el consumo de determinadas sustancias.

8 En el juego Leonardo da Vinci arregla la hoja oculta de Ezio, véase el vídeo en https://www.youtube.com/watch?v=R74TjipiLq0, lo cual no significa que la inventara, como en algunos foros se da por sentado. Incluso se muestran los presuntos planos de Leonardo que no son sino una adaptación de los dibujos originales que se referían a sus cuadernos de anatomía.
}

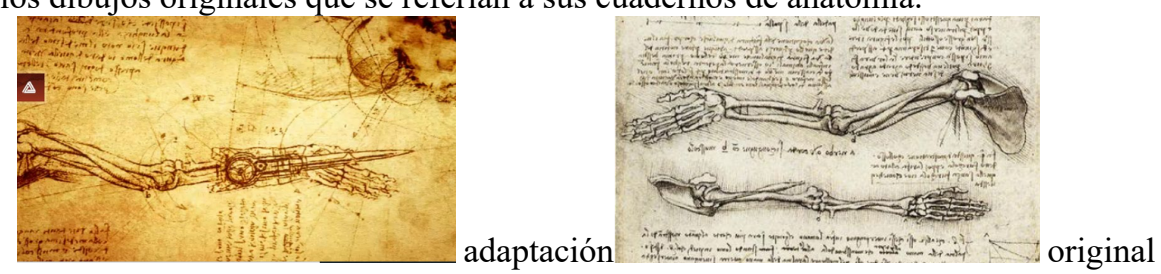




\section{$\Delta A$}

Lo cierto es que el símbolo se asemeja mucho a la escuadra y el compás característicos de la masonería, y presentes en algunas escenas de los juegos, como veremos más adelante, si bien, nunca asociados al siniestro grupo de los assassins.

\section{Templarios}

En lo que respecta a los templarios las fuentes son más concretas y fidedignas, pero tampoco están exentas de un importante halo de leyenda. De entrada, ni siquiera hay unanimidad en lo que a la fundación de la Orden se refiere ${ }^{9}$, pero sí tenemos claro que ocurrió entre 1118 y 1121, que fueron nueve caballeros liderados por Hugo de Payns y que tras el Concilio de Troyes de 1128, en el que también se aprobó la Regla por la que se iban a gobernar y que había sido encargada a Bernardo de Claraval, el papa Honorio II autorizó eclesiásticamente la congregación ya fundada que será denominada Orden de los Pobres Caballeros de Cristo y del Templo de Salomón (Pauperes Conmilitones Christi Templique Solomonici), más conocidos como Caballeros Templarios.

El complejo entramado económico-financiero que crearon a través de las Encomiendas, unido a su dramático final, de sobra conocido ${ }^{10}$, es, sin duda, lo que más ha influido en la forja de la leyenda y fue a partir de 2001, a raíz de que la investigadora italiana Bárbara Frale hallara el Pergamino de Chinón en la Biblioteca y Archivos Secretos Vaticanos ${ }^{11}$, cuando se reavivará la fiebre templaria.

No nos vamos a referir en estas páginas a la historia del Temple, salvo en los casos o en los momentos que sean necesarios, porque con excepción de la primera entrega, la de las Cruzadas, los caballeros de la Cruz Patada no aparecen en su forma real y sirviendo a los fines para los que se organizaron.

\footnotetext{
${ }^{9}$ Para algunos, fue en 1118, coincidiendo con la coronación de Balduino II como rey de Jerusalén y la presentación ante este de los nueve caballeros, ofreciéndose para proteger a los peregrinos que fueran a Tierra. Para otros, sería en 1119, debido a que toman como referencia el viaje de Hugo de Payns a Europa. E, incluso, para ciertos grupos, sería en 1120, ya que en numerosos escritos se cita que el Concilio de Troyes se celebró nueve años después de la fundación del Temple. Sin embargo, como apunta José Luis Corral en su Breve Historia del Temple, todo depende del calendario por el que se date el hecho. El Concilio de Troyes se convocó el 14 de enero de 1128, pero se data por el año de la Encarnación y no del Señor, de modo que de acuerdo con el año del Señor y a nuestro calendario actual, sería 14 de enero de 1129.

A esto debemos añadir otra variable, y es el hecho de que entre los siglos X y XVI la dinastía de los Capeto se regía por el año de la Resurrección, que se inicia el Domingo de Resurrección, y que es muy complicado de traspasar a nuestro calendario, puesto que el domingo de Pascua no tiene fecha fija.

${ }^{10} \mathrm{La}$ tragedia de Jacques de Molay aparece perfectamente recreada en el juego, véase el siguiente enlace al vídeo: https://www.youtube.com/watch?v=jUfHvU4hrxU

${ }^{11}$ En el manuscrito, fechado en agosto 1308 en la Diócesis de Tours, el Papa Clemente V absuelve -que no disuelve- a la Orden del Temple de los cargos por los que se les había detenido y condenado: herejía, idolatría, homosexualidad y prácticas obscenas.
} 
4 Abstergo

En el mundo de Assassin's Creed, Industrias Abstergo es una multinacional del mundo actual al servicio de los Templarios ${ }^{12}$.

Bajo apariencia de industria farmacéutica, es responsable de importantes avances tecnológicos cuyo único fin es acabar con la Orden de los Asesinos a través del Animus, una suerte de máquina de realidad virtual que, a través del ADN de una determinada persona, permite acceder a sus recuerdos de otras épocas.

\section{Breve sinopsis de la trama}

Una vez ubicados los grupos con los que nos vamos a encontrar, haremos un breve resumen del argumento.

Corre el año 2012 el camarero Desmond Miles es secuestrado por parte de la compañía farmacéutica Industrias Abstergo. Una vez allí, Miles es obligado a entrar en el Animus, un aparato que le permite ver los recuerdos de sus ancestros. En el primer juego, accede a la memoria del maestro asesino de la Tercera Cruzada el sirio Altaïr Ibn-La'Ahad. El objetivo de Abstergo es encontrar los denominados Fragmentos del Edén, artefactos capaces de apoderarse de las mentes humanas para lograr una sociedad civilizada y en paz. Este es el motivo de una guerra secular entre Assassins y templarios.

En Assassin's Creed, la acción se desarrolla en las ciudades de Damasco, Acre y Jerusalén, durante la Tercera Cruzada. El protagonista Altaïr deberá asesinar a nueve objetivos históricos. Entre ellos, cuatro importantes cruzados como Robert de Sablé, décimo primer Gran Maestre del Temple ${ }^{13}$.

Assassin's Creed II era la segunda parte de una trilogía, pero cambia el protagonista y el escenario. Ezio Auditore de Florencia es un joven florentino de clase acomodada, antepasado de Altaïr aunque él lo desconoce. Los ambientes recreados son Florencia, Venecia y Roma. De nuevo convive con destacados personajes de la época, que engrosan las filas de ambos grupos: los Medici, Da Vinci o Maquiavelo del lado de la Hermandad; los Borgia del lado templario. Como en el caso anterior, las misiones consisten en acabar con una lista de supuestos templarios.

Assassin's Creed Brotherhood: Protagonista y escenarios coinciden con respecto a la entrega anterior. Tras recuperarse de las heridas de los combates, regresa a Roma con el fin de acabar con el poder de los Borgia, en especial, con la vida de César, recuperar el Fruto del Edén; y acabar con los templarios ${ }^{14}$.

\footnotetext{
${ }^{12}$ También el anagrama de Abstergo guarda una evidente similitud con triángulos masónicos.

${ }^{13}$ Se puede consultar el vídeo en la siguiente dirección: https://www.youtube.com/watch?v=k3xgRfRc1IY

${ }^{14}$ En esta entrega la leyenda negra que persigue a la familia Borgia sirve para presentarlos como avatar del poder desmesurado, de los vicios más depravados e incluso del asesinato con el único fin de justificar una actuación equivocada. Nada más alejado de los fines de la Orden del Temple.
} 
Assassin's Creed Revelations: Ezio, ya mayor, se traslada a Masyaf para encontrar secretos ocultos de Altaïr y de allí a Constantinopla. Su misión es conseguir las cinco llaves que dan acceso a la Biblioteca de Altaïr, pero una está en poder de los templarios. Estamos en el año 1512, en la época de Selim I, padre de Solimán el Magnífico.

Con Assassin's Creed III se da un considerable salto en el tiempo y la acción se traslada a mediados del siglo XVIII, a los albores de la Guerra de Independencia americana (1775-1783). El enfrentamiento entre los dos grupos continúa. Sin embargo, para intentar dar credibilidad a la historia el protagonista, Connor Kenway, hijo de un templario, acaba situándose del lado assassin. A lo largo del juego se reúne con los líderes de la época: George Washington, Benjamin Franklin, Thomas Jefferson, Charles Lee, Israel Putnam, Paul Revere, el Marqués de La Fayette, John Pitcairn, Samuel Adams y es precisamente en esta entrega donde más referencias a la masonería localizamos.

Tras este breve análisis, en el que no hemos querido desvelar entresijos del juego, nos encontramos, de un lado, a los assassins, los buenos desde el punto de vista de la trama, para quienes los humanos deben ser libres y decidir sin ningún tipo de condicionante. Y, por otro, están los templarios, quienes consideran que las personas han de estar supervisadas por un grupo de líderes que impida que haya conflictos. Dejando a un lado qué bando tiene más o menos razón, o sus posibles conflictos éticos, la realidad histórica nos indica que a finales del siglo XV y comienzos del XVI, el período que abarcarían las tres entregas de Ezio, ya no existía ninguna de las dos organizaciones, ni assassins, ni templarios por lo que situarlos en esos escenarios es mera ficción. De igual modo, tampoco existía la masonería como institución, mientras que las asociaciones gremiales, que tanta importancia tuvieron durante la Edad Media debido a la construcción de las grandes catedrales góticas, en especial los gremios de canteros y picapedreros, habían comenzado su declive.

Tal y como refiere el profesor Ferrer Benimeli ${ }^{15}$, a lo largo del siglo XVIII está constatada la presencia de personajes aficionados al arte de la construcción al lado de operarios que trabajaban la piedra. Son los denominados accepted masons, que sirvieron de unión entre la masonería operativa y la especulativa a finales del siglo XVII. Esta transición se materializó en 1717, fecha de creación de la Gran Logia Unida de Inglaterra, si bien recientes investigaciones del profesor Prescott ponen en duda este dato ${ }^{16}$. El proceso culminó en 1723 con la publicación de las Constituciones de Anderson, verdadero documento ideológico y fundacional de la masonería moderna.

En el momento del levantamiento de las Trece Colonias, la masonería no solo existía, sino que había llegado y se había implantado en suelo americano, siendo casi todos los personajes que aparecen en el juego y que interrelacionan con Connor destacados

\footnotetext{
${ }^{15}$ José Antonio Ferrer Benimeli, La Masonería (Madrid: Alianza Editorial, 2005).

${ }^{16}$ Andrew Prescott, "A History of British Freemasonry 1425-2000", CRFF Working Paper Series 1 (2007): 129, http://ww.nebraskamasoniceducation.com/masonichistory/historyofBritMasonry.pdf
} 
integrantes de la Institución. De hecho, se menciona la Green Dragon Tabern conocido lugar de reunión de los masones y patriotas americanos, y directamente implicada en el Boston Tea Party. Aparentemente esto implica un giro en la concepción de la trama pues unos son situados del lado templario que pasa a ser identificado con la escuadra y el compás y otros personajes, como George Washington, aparentemente neutrales y conocidos francmasón de la época, aceptan la alianza con un Assassin, como Connor.

De esta manera, la masonería aparece en escenas de esta quinta entrega, pero no como Institución sino asociada a los templarios ${ }^{17}$. Y es así como se siguen alimentando

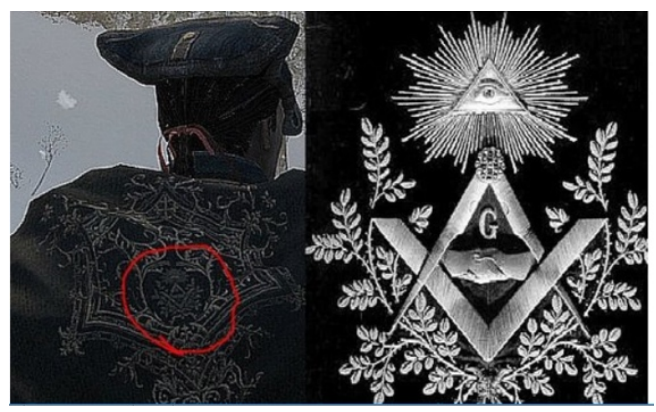
mitos y bulos del tipo: "Los francmasones han declarado varias veces ser descendientes de los caballeros templarios, además de guardar muchos de sus secretos". "La francmasonería esconde los tesoros templarios" $"$.

Casi más evidentes son las imágenes en las que se muestran abiertamente la escuadra y el compás en los subterráneos de Boston. Para nuestra sorpresa, y para introducir algo más de confusión, los triángulos encendidos son considerados como simbología Iluminati ${ }^{19}$. Se pueden encontrar mensajes tanto directos como subliminares.
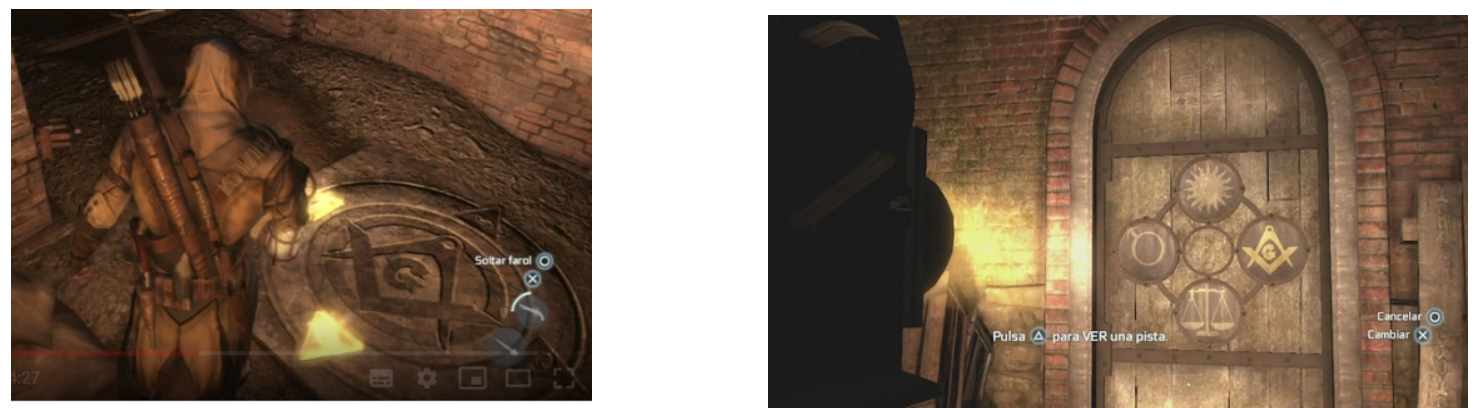

En algunas secuencias del juego aparecen frases como "soy un iluminado", "debemos crear un Nuevo Orden Mundial" o "en nombre de la luz y la sabiduría". Se pueden ver continuamente pirámides, ojos o compases illuminatis" 20 .

17 La capa de Haytham Kenway, padre de Connor, se puede observar en la siguiente dirección: https://www.3djuegos.com/comunidad-foros/tema/23848369/0/porque/ AC3

18 Revísese la siguiente dirección: https://www.vix.com/es/btg/curiosidades/6838/7-mitos-sobre-loscaballeros-templarios-que-aun-siguen-en-pie

${ }^{19}$ Los iluminados de Baviera fueron fundados en 1776 por Adam Weishaupt y se supone que el juego está ambientado en un momento anterior, de modo que se debe poner duda el hecho de que se les relacione en esta entrega. Sobre esta sociedad, ver Daniel Ligou: Dictionnaire de la franc-maçonnerie (París: Presses Universitaires de France, 1987), 609; Lorenzo Frau Abrines, Diccionario Enciclopédico de la Masonería (México: UEM, 1977), 595.

${ }^{20}$ Sitio Web del videojuego: https://www.3djuegos.com/comunidad-foros/tema/20085278/0/assassins-creedun-juego-illuminati/ 
Sin duda, ninguno de los de foros o de los canales de YouTube son fuentes autorizadas, y generalmente publican sinsentidos con el agravante de la enorme difusión que tienen, dando por buenas y fiables afirmaciones que meten en el mismo saco a sociedades secretas, órdenes religiosas, y sectas de asesinos ${ }^{21}$.

\section{Conclusión}

Lo que hemos querido recoger a lo largo de estas páginas no es ni la historia de la hermandad de los Hashshashin ni la de la Orden del Temple, ambas sociedades rodeadas y mediatizadas por un halo de leyenda tan fundido y confundido con la historia que resulta difícil discernir la realidad de la ficción. Lo que hemos intentado plasmar es cómo hoy día, transcurridos más de siete siglos desde la desaparición de los dos últimos grandes maestres, Jacques de Molay y el «Viejo de la Montaña» siguen siendo actualidad. En este sentido, la trama de los juegos cumple con el requisito de la vigencia, consiguiendo trasladar una historia del siglo XI al siglo XXI. Sin embargo, el trasfondo de los juegos es una mezcla de supersticiones y ficciones con teorías de la conspiración. Es una reescritura de la historia tan bien hecha que es capaz de convencer de que lo ocurrido en el juego es verdad. Quizá este sea el atractivo de la cultura pop valorar, en este caso videojuegos, no por sus aportaciones a la cultura sino por criterios mediáticos y estéticos tan vagos como "es flipante".

Es cierto que el templarismo vuelve a estar de moda, que la desaparición de la Orden en las circunstancias en las que ocurrió ha dado lugar a toda una novelesca en torno a su posterior evolución $\mathrm{y}$, sobre todo a la identificación de determinada imaginería simbólica cargada de contenido esotérico con otras hermandades, sociedades e instituciones. La masonería operativa convivió con la Orden del Temple y el Temple convivió con los Assassins, pero de ahí a confundir a templarios con masones y con Iluminati hay un camino tan grande como equivocado.

Hemos tratado de dar una visión científica construida a partir de hechos verificables y documentación de origen más que comprobado, ya que el enfoque de los juegos trata sin duda de colocar a la Orden del Temple y a la Masonería dentro del contexto de la tradición de los misterios del ocultismo, comparando las enseñanzas, las alegorías y el simbolismo de cada organización y oficio con otros de corte parecido, pero pertenecientes al ámbito del esoterismo.

La saga de videojuegos recrea los marcos históricos y los personajes con verdadera maestría, siendo muy útiles para situarse en las diferentes épocas. Sin embargo, en relación con el tema que nos ocupa, Assassins, templarios-masones, creemos que solo ha

\footnotetext{
21"Ha habido varias sectas como, los masones y los iluminati, los templarios, la Compañía de Jesús, los rosacruces que tomaron parte de las estructuras de los Hashshashins para sus sectas".
} 
conseguido seguir alimentando la fábula de los poderes ocultos que conspiran para crear un nuevo orden mundial. En definitiva, los mismos mitos que persiguen a la masonería moderna desde su fundación en el siglo XVIII.

Pero si alguien conoce de verdad un videojuego es quien se recrea con su uso, por eso, dedico este trabajo a quienes disfrutan a ratos y soportan mis interminables preguntas cada vez que lo hacen. A mis hijos Pablo, Javier, Juan y Álvaro, así como a mi amiga Andrea, pues sin ellos no hubiera accedido a estos contenidos.

\section{Bibliografía}

Ambelaine, Robert. La Symbolique des outils dans L'Art Royal. París: Editions du Prisme. 1975.

Bartol, Vladimir. Alamut. España: EL ALEPH, 2003.

Boucher, Joules. La Symbolique Maçonique. Paris: Devuy, 1948.

Bowden, Oliver. Renaissance. Madrid: La esfera de los libros, 2010.

Bowden, Oliver. La hermandad. Madrid: La esfera de los libros, 2011.

Bowden, Oliver. La cruzada secreta. Madrid: La esfera de los libros, 2012.

Bowden, Oliver. Revelaciones. Madrid: La esfera de los libros, 2013.

Corral José Luis. Breve Historia del Temple. Barcelona: EDHASA, 2006.

Espinar Lafuente, Francisco. Esquema filosófico de la masonería. Madrid: Itsmo, 1981.

Frau Abrines, Lorenzo. Diccionario Enciclopédico de la Masonería. México: UEM, 1977.

Ferrer Benimeli, José Antonio. La Masonería. Madrid: Alianza Editorial, 2005.

Ferrer Benimeli, José Antonio y Susana Cuartero Escobés. Bibliografía de la Masonería. Madrid: Fundación Universitaria Española, 2004.

Findel, I. G. The History of Freemasonry from its origin down to the present day. London: Asher \& Co, 1927.

Ligou, Daniel. Dictionnaire de la franc-maçonnerie. París: Presses Universitaires de France, 1987.

Mackey, Albert G. Lexicon and History of Freemasonry. Filadelfia: McClurePublishing C.O, 1910.

Morales Miranda, J. Ritos y secretos de la antigua Francmasonería. Madrid: Erisa, 1980.

Prescott, Andrew. "A History of British Freemasonry 1425-2000”. CRFF Working Paper Series 11 (2007): 1-29. http://ww.nebraskamasoniceducation.com/masonichistory/historyofBritMasonry.pdf 